Western University

Scholarship@Western

FIMS Publications

Information \& Media Studies (FIMS) Faculty

2021

Documenting multiple temporalities

\author{
Pam McKenzie \\ University of Western Ontario, pmckenzi@uwo.ca \\ Elisabeth Davies \\ edavies3@uwo.ca
}

Follow this and additional works at: https://ir.lib.uwo.ca/fimspub

Part of the Library and Information Science Commons

Citation of this paper:

McKenzie, Pam and Davies, Elisabeth, "Documenting multiple temporalities" (2021). FIMS Publications. 368.

https://ir.lib.uwo.ca/fimspub/368 


\title{
Documenting multiple temporalities
}

\section{Accepted for publication to Journal of Documentation 2021}

\author{
DOI: $10.1108 / J D-11-2020-0196$
}

\section{Introduction}

Everyday life in developed countries in the early $21^{\text {st }}$ century often demands the navigation of an array of interwoven threads of activity across various domains (e.g., work, health, family, Beech et al. 2004, Grimes and Brush 2008, Leshed et al. 2014, McKenzie and Davies 2021, Ocepek 2018). The mobility afforded by coordination technologies such as cellphones and e-mail allows activities from various domains to pervade life regardless of physical location. Hochschild (1997) argues that round-the-clock demands of paid employment and unpaid household work create the need for a "third shift" of work to manage, monitor, and repair ever busier lives. Much of this third shift consists of what Star and Strauss $(1999,10)$ call articulation work, "work that gets things back 'on track' in the face of the unexpected, and modifies action to accommodate unanticipated contingencies." Considerable day-to-day articulation work may be required to "keep track," coordinate people and resources in time and across physical and organizational settings, monitor and document the coordination process, and remind oneself of what must be done and remembered and when, where, and by whom.

Standardized tools for keeping track, such as calendars and schedules, create a common framework for classifying, allocating, documenting, and managing time. However, temporal categories such as durations and periods do not form a single coherent system. The embodied time of a person's biological needs may conflict with the "clock time" of shift work, which requires rotating "natural" rhythms of eating and sleeping around the clock as work patterns change. A single word may refer to different temporal periods both across and within domains or activities. Everyday life, then, requires the integration of multiple temporalities (e.g., clock time, body time, and individual biography time) and the navigation of multiple meanings of "standard" time words.

This article analyzes the creation and use of calendars, planners, and other cognitive artifacts (Hutchins 1999) to document multiple temporalities in everyday life. It shows how these tools embed multiple temporal logics at several timescales and presents the articulation work involved in documenting multiple temporalities and navigating situated meanings of seemingly standard time words. It shows how this work is at once customized to the individual documenter's circumstances, and embedded within broader social and temporal contexts and infrastructures.

\section{Literature review}

Calendars, planners, schedules, and timetables constitute what Hutchins (1999) calls "cognitive artifacts," objects created with the purpose of supporting cognition. Many cognitive artifacts are "actionable" (Whittaker, 2011, p. 40); the calendar itself supports prospective memory of future events and plans by reminding its user to complete the items on it (Scullin et al 2015). Research in library and information science (LIS), human-computer interaction $(\mathrm{HCl})$, and computer-supported cooperative work (CSCW) shows that people use cognitive artifacts such as calendars and planners for reasons apart from future functional value, that organizational systems of multiple documents are common to manage the differing needs of different domains, and that users may prefer the flexibility of paper systems even in highly computerized environments (Beech et al. 2004; Brush and Turner 2005; Dittmar and Dardar 2014; Eliot, Neustaedter, and Greenberg 2007; Grimes and Brush 2008; Leshed 2012; Leshed and 
Sengers 2011; Palen 1999; Payne 1993; Swan and Taylor 2004; Plaisant et al. 2006; Tomitsch, Grechenig, and Wascher 2006; Tungare, Pérez-Quiñones, and Sams 2008).

This body of research uses ethnomethodologically-informed approaches that pay close attention to the micro-level hows (Holstein and Gubrium 2011) - the situated and material ways that people "do" social life (Crabtree 2003), and acknowledges the flexible, contingent, and contextual ways that cognitive artifacts may be created and used in individual households, workplaces, and other locations. Studies show that cognitive artifacts perform relational as well as instrumental functions (e.g., Thayer et al. 2012, McKenzie and Davies 2021), that individuals and families exploit household routines to ensure that the right person sees the right artifact at the right time (Eliot, Neustaedter, and Greenberg 2007), and that cognitive artifacts become accountable through their ongoing creation and use by household members (Crabtree et al. 2003).

A complementary body of scholarship attends to the macro-level whats (Holstein and Gubrium 2011) of documentation practices: the location of everyday practices within a complex of infrastructures, institutions, and discourses that operate beyond individual homes and workplaces. This scholarship understands information and documentation practices to be constituted between people and nonhuman actors, and out of relations among people within explicit or implicit communities (Courtright, 2007, p.296). It brings to light the ways in which cognitive artifacts are embedded in and organized by larger socio-cultural systems and by institutional and technological factors. Although individuals may create and use cognitive artifacts in idiosyncratic and profoundly personal ways, these practices both draw their conventions from and contribute to the persistence of larger infrastructures (Star 1999, Trace, 2002, 2007, Shankar 2009).

Documentation is therefore not just something individuals do in isolation, and cognitive artifacts for keeping track do more than just coordinate people and resources in time and space. The act of documenting makes some things visible and others invisible. A calendar orders chaos (Shankar, 2007) in ways that make that order seem natural and erase the work done to achieve it. The way that documents are created, arranged, and used gives shape to and sustains organizational systems (Shankar, 2009, p. 161). At the same time, local practices reveal the broader context, as infrastructures become visible on breakdown (Star 1999, p. 382).

By attending to the ways that cognitive artifacts are a) locally created and b) embedded in broader contexts and infrastructures, each body of research goes beyond positivist, objectivist, and cognitivist stances that "wip[e] away" the difference between representation and reality and see cognitive tools as transparent providers of information about "what really happens" (Johansson, 2012, Trace, 2002). However, they largely operate on the implicit assumption that time is unitary. In doing so, they naturalize the temporal logics underpinning these tools "in such a way as to be beyond challenge." They therefore take for granted the ubiquity, validity, and usefulness of these logics, which have "great power to frame and organize behavior" (Birth, 2013, p.220). Together, these two bodies of scholarship address the local and situated articulation work required to document multiple temporalities, and the ways that that work is situated within broader social and technical. This article builds on these two bodies of scholarship by making visible the "pragmatics and invisible forces of [temporal] standards and categories in the modern built world" (Bowker and Star 1999, 3) that shape the design and use of cognitive artifacts.

\section{Multiple temporalities and articulation work}

Sociologist Barbara Adam (1995, p.6) argues for a study of time as social time, which requires "a move 
beyond the time of clocks and calendars and to make explicit what constitutes a largely unreflected aspect of contemporary social science: time embedded in social interactions, structures, practices and knowledge, in artefacts, in the mindful body, and in the environment." She argues $(1990,1995)$ that individuals and organizations are quite skilled at conflating a wide variety of time concepts (e.g., body and individual biography time as well as clock, calendar, agricultural, astronomical, project, social, cultural times) and living within them as though they were coherent.

Navigating multiple temporalities requires many forms of articulation work beyond simple time management, a concept that itself "remains focused upon, and bounded by, a very rational clock-time view" (Sabelis 2001, p.390). This work includes the categorization of temporal units, the development and communication of working taxonomies, the documentation and management of temporally-related personal information (e.g., McCoy, 2009), and the reconciliation of temporal incommensurabilities, both within individual schedules and between one person's schedule and others' (Flaherty 2003, Southerton 2006). Whether in homes, workplaces, or elsewhere, some patterns of activity, such as appointments, translate easily into clock-time units, which makes them easy to schedule and coordinate across individuals. Others, such as projects (Adam, 1995) or care tasks (Sabelis 2001, Bowker and Star 1999), do not. Cognitive artifacts such as calendars, planners, timetables, and schedules provide a structured canvas, a form or template, for documenting time. Although we treat new calendars as though they are blank, they come pre-populated with temporal logics. They include a duration, generally a calendar year. They typically adopt a matrix format, expressing days of the week on the top row and repetitions or subdivisions along the first column. They categorize time into individual elements (days, with the planner further subdividing each day into hours or half-hours) and represent the cyclical repetition of occurrences over a day, a week, or a month. Spreadsheets offer further flexibility to define the matrix elements, enabling them to function in project management, mapping project activities against time (Larson and Gray, 2014). Like periodic tables (Hjørland, 2011), these tools allow for the representation of both individual entities and the periodic relationships among them. For example, railway timetables replicate a particular rail journey's itinerary and stops, while the grid communicates the "uniformity and linearity" (Symes, 2011, p. 157) of railway time.

Although calendars based on Gregorian calendrical logic may appear to represent homogeneous time, Birth (2013) argues that they do not erase other time systems. Calendars embed anachronistic features: the word "month" reflects the charting of lunar cycles to which Gregorian months do not adhere. Trinidadian wall calendars include nationally-recognized Christian and lunar-calendar Muslim and Hindu festivals "through a Gregorian medium" (Birth, 2013, p. 228), which means that they appear to move from year to year, as would a Christian holiday if represented on a Muslim or Hindu calendar (Birth, 2013, p.231). The varying rhythms create a reliance on the calendar, compelling the use of wall calendars to verify the dates of important festivals and ensuring their placement in a location where they can be readily seen and consulted.

Everyday life, then, entails navigating and documenting multiple temporalities. In addition to being situated within broader social and technical contexts, the practices of documenting time and the cognitive artifacts designed to support documentation are themselves are situated within, and shaped by, temporal logics and infrastructures. This article explores the micro-level practices and broader contexts of documenting time from a broader study of the work that individual Canadians do to keep track across multiple domains of everyday life.

\section{Study design}


The study is situated within a broad theoretical perspective that Holstein and Gubrium $(2011,342)$ call an analytics of" interpretive practice." This perspective combines ethnomethodologically-informed approaches that pay close attention to the micro-level hows with approaches that attend to the macro-level whats. The objectives of the overall study are (1) to identify and describe the material, embodied, situated practices through which individuals keep track, (2) to understand how that work is organized within household/family contexts, (3) to understand how the everyday work of keeping track is connected to the goals and requirements of institutions such as employment, education, and healthcare and the physical, environmental, and social infrastructures of everyday life; and (4) to analyze the ways that discourses of workplace and domestic life are taken up in people's talk about keeping track and, conversely, how keeping track figures into their descriptions of their lives and selves.

\section{Data Collection and Participants}

With a team of research assistants, we interviewed 47 participants (31 identified as women and 16 as men) about how they keep track in their everyday lives. Participants resided in two Canadian provinces (three in Nova Scotia and 44 in Ontario) and interviews took place between 2010 and 2015. Because the study sought to understand the practices of keeping track across the multiple domains that comprise everyday life (McKenzie and Davies 2021), we recruited for diversity in participant contexts including domestic arrangements (e.g., living alone, with roommates, sharing custody of children), employment circumstances (e.g., home-based businesses, shiftwork, gig and contract work, multiple jobs, unemployed), and other everyday life roles (e.g., student, hobbyist, person managing a chronic illness). Consistent with other studies of the use of cognitive artifacts for documenting time (e.g., Neustaedter et al. 2009), we set out to recruit a sample of 40-60 participants and ceased data collection when the sample represented reasonable breadth on these criteria.

The interviewers asked two broad, general questions (What do you need to keep track of? How do you do it?). We did not define "keeping track," but allowed participants to interpret as they wished. We probed as appropriate to invite each participant to elaborate. Interviews averaged 73 minutes long and ranged from 41 to 131 minutes. We interviewed participants in locations of their choosing (homes, workplaces, or coffee shops). When we interviewed in homes and workspaces, we invited participants to show us the spaces and tools they used for keeping track. Interviews in coffee shops were limited to discussing and observing what the participant mentioned or had brought with them. We supplemented the interviews with a nonparticipatory visual method (Pollak 2017); we asked permission to photograph objects and spaces we discussed and/or observed over the course of the interview. We took photos during and/or immediately after the interview concluded. The data set includes 56 hours of recorded interviews (2200 transcript pages) and 1175 photographs. Data collection and analysis adhered to Canadian guidelines on ethical research on human subjects (Canadian Institutes of Health Research et al., 2018). To maintain confidentiality, we identify participants by a generic descriptive phrase.

\section{Data analysis}

This article addresses the first three objectives of the broader study with reference to documenting

time. Data analysis followed several recursive steps using strategies of constant comparison (Corbin and Strauss, 2007). The first author used NVivo 12 to code the transcripts thematically (Braun and Clarke, 2006) for mentions of cognitive artifacts such as calendars, schedules, timetables, planners, and spreadsheets. She also coded transcripts thematically for words and phrases indicating facets of temporality (Southerton 2006), including words that indicate duration (such as shift, day, season, year; holiday words including birthday and anniversary); tempo (busy, slow), periodicity (regular, rare), sequence (before, after), and descriptions of timing (the synchronization or mutual adaptation of 
events, e.g., the need to leave work early to pick up a child for a dental appointment), and reviewed photographs of cognitive artifacts for annotations reflecting facets of temporality.

Analysis employed Holstein and Gubrium's (2011) strategy of "analytic bracketing," which allows for close attention to both the situated and material ways that people "do" everyday life and the ways that everyday life is materially and discursively situated in broader social, economic, geographic, and temporal contexts. This approach requires constant shifting between the local practices and their broader context, attending to the ways that individuals' practices are situated with respect to institutions, ideals, and discourses.

The analytic approach is concerned with making visible the socially situated practices of articulation work required to document multiple temporalities, the role of temporalities in everyday document work, and the ways these are embedded in and reproduce broader norms, standards, and infrastructures (Bowker and Star 1999, Trace, 2007, Star 1999). The article therefore does not analyze the extent to which given temporalities were evident, nor identify all of the temporalities at play; rather it identifies the ways that different temporalities shape the ways participants created and used documents in keeping track.

\section{Findings}

This section begins with an exploration of two micro-level features of documenting time. First, it uses a photograph from a planner to illustrate the ways that multiple temporalities intertwine in a single participant's documentation practices. Next, it uses transcript excerpts and images to highlight the "multiple, composite, simultaneous, open-ended and changing" (Adam 1995, 6) meanings of time words at several scales (periods within a day or week, the meaning of a "day," and longer periods within a year). It shows how participants navigated multiple contextually-relevant meanings and identifies breakdowns that reveal the temporal infrastructures (Star 1999) underpinning the cognitive artifacts participants used.

The second half of this section delves more deeply into two the cases of two participants, a professional musician and market-garden farmer, situating their articulation work within their broader social, economic, and temporal contexts. These cases were chosen for their similarities as well as their differences. Both participants were self-employed in home-based sole-proprietorship businesses, although much of their work took place outside the home. Both were dependent on contingent contracts or gigs and their work was entrained to external cycles. The specifics of those cycles differed, as did the overall approach they used for documenting time. The musician used an off-the-shelf tool, a printed paper agenda, to keep track, whereas the small farmer took a do-it-yourself approach, creating multiple spreadsheets and custom monthly calendars. Focusing on these two cases shows how articulation work is customized to individual circumstances and shaped by the choice of documentation tools, while both the practices and the tools are embedded within broader social and temporal contexts and infrastructures.

Direct quotes have been edited for brevity and clarity (e.g., removing false starts and irrelevant text). Bracketed ellipses indicate removed text.

\section{Documenting multiple temporalities}

Insert Figure 1 about here 
Figure 1. Documenting multiple temporalities

Figure 1, an image from a paper planner, illustrates one participant's documentation of multiple temporalities within a few days of calendar time.

This participant worked full-time, took a night class and shared custody of a child with an ex-partner. These multiple everyday life domains (e.g., work, family, school) were evident in her planner, as were multiple temporalities. The planner was structured around the Gregorian year. Civic time came pre-printed in the form of the Canadian Remembrance Day, which is a provincial holiday in some places, though not in the province where this participant lived. The presence of the American Veteran's Day holiday reflects the closeness of the Canadian and American economies: the same calendar might be available for purchase in both countries, and two of our participants worked in the U.S. so needed to be aware of American holidays.

Clock and calendar time appear in the form of appointments: a Skype call, class times, and a day surgery appointment. Some temporalities, such as weekly class time, align with the Gregorian template. However, as Hindu holidays appear to move across the pages of a Gregorian calendar, the eight-day cycle of "garbage day" in her city marches diagonally across each row of a seven-day week view (McKenzie 2020). Additionally, the planner references seasonal time: yard waste pick-up occurs every two or three weeks in the spring and autumn; the entry in this November calendar page references the falling leaves of autumn. Biological time is documented by the inclusion of a sick day, a reminder of a colleague coming back part time after a medical leave, and the use of a cryptic symbol to mark the beginning of the participant's menstrual cycle. The planner documents the timing of the custody arrangements she has made with her ex-partner and notes the two days each week that her child is “@” their other parent's home. Biographical time appears in the notations of friends' birthdays. Project time coexists with clock time in a reminder of a class presentation. Event time appears in the form of a "chili lunch," a workplace fundraiser. Contextually-situated time words appear, including a due date for library books (different libraries have different borrowing periods) and the observation that her partner has a "busy day" and a "free evening."

This image represents the range of temporalities participants integrated into their everyday lives and documented through their cognitive artifacts.

\section{Situated meanings of time words}

One of the funniest lines in the Canadian comedy series Schitt's Creek occurred when Alexis Rose (played by Annie Murphy) attempted to bond with her soap-opera star mother Moira (played by Catherine O'Hara) by asking what her favourite season was. Moira responded, "Awards" (Peacocke, 2017). The success of the joke rests on the fact that time words have contextually-situated meanings; the same word may refer to different temporal periods for different people, depending on the person's role or function. For example, the "busy day" documented in Figure 1 is contextual in two senses; first, this day is "busy" for the participant's partner, but not necessarily for anyone else, including her. Second, another person faced with the same set of activities may not consider the day "busy."

A single word may refer to a different clock-or-calendar- time duration or start/end point. These contextual meanings can operate at any time scale, from "just a second" to "the end of an era". For example, a "day" can be 24 hours, the period from sunrise to sunset, or an 8-hour "day shift" as compared to an "afternoon" or "night" shift. "The last minute" is rarely 60 seconds long. "Season" 
means different things to a farmer, an athletic coach, a person with Seasonal Affective disorder, and a soap-opera star.

Such contextually contingent categories of time depend on socially and culturally shared meanings for significance (Adam 1995). As a university teaching assistant participant told us,

Obviously you can't be meeting with students or holding office hours at four o'clock in the morning. I mean you could, but nobody would show up.

To be successful, "office hours" need to take place during "regular" university hours when students will attend. Davies' (2007) theatre production professionals used different words to describe what appeared to be the same period of calendar time: "Prep week" was crucial to stage managers, but for the actors, this period was just the unnamed week before rehearsal. Contextual significance extends to the classification of time as "ordinary" in comparison to "extraordinary" times such as holidays (Hancock and Rehn, 2011) and crises. Our participants engaged in articulation work to manage the contextual demands of the underlying temporalities, both against one another and against the temporalities embedded in the cognitive artifacts they used to do that work (Birth, 2013). The remainder of this section describes participants' documentation of periods within the course of a day or week, days themselves, and contextual periods longer than seven days.

\section{Periods within the course of a day or week}

Many participants did not document regular occurrences that were invariant and predictable. A participant who regularly worked out of town on Mondays did not document this on the wall calendar she shared with her spouse, observing that "It's a given." "Lunch" was a given for many participants, but not for all, and it appeared in several calendars and schedules.

One participant was trying to develop a more consistent plan for each day to balance the demands of family, a home-based small business, and a chronic illness. "Lunch" was a focal point for this effort, since the morning's work often expanded to fill the regular clock-time lunch slot that was beneficial to their physical and mental health. Breakfast, which took place before work demands began to interfere, did not need a written reminder.

Participant: I try to have lunch around the same time every day. I have it in my calendar or else I forget to do it. [...] Interviewer: Do you always have to write breakfast in or...?

Participant: No, I will remember breakfast.

For front-line service staff, "lunch" is a period away from work. An administrative assistant showed us the workplace calendar she used to document appointment times for two service staff members who had coordinated their lunch breaks (one at noon and one at 1 PM) to ensure seamless availability for appointments.

And they put their lunches in because they try to alternate, so if a [client] needs help at least somebody's available.

\section{Insert Figure 2 about here}


Figure 2. Restaurant Lunch

For restaurant staff, "lunch" is a working shift. The schedule illustrated in Figure 2 was posted in a back-of-house work area. It shows how "lunch" was a term flexible enough to accommodate daily differences in the eating patterns of diners and the variable work hours of restaurant staff. What "lunch" means may be different on each day, depending on how busy it is and how many staff are available. Tying the contextually-relevant term to clock time enables the manager to specify "lunch" in terms of start and end times and working hours for each employee. These may vary according to the employee's availability, the hours worked so far this week, and how close the hours are to the maximum allowed under provincial labour legislation. For employees, the schedule provides the template from which to update their personal calendars and planners to schedule work into their own day, and around their own "lunch." For all staff, the schedule gives an at-a-glance view of who is "on" this lunch shift.

The articulation work related to the word "lunch" allowed all three participants to coordinate embodied time (hunger and eating, and in one case, physical and mental health) with organizational time (managing workflow and ensuring consistent employee availability).

Days: religious and secular temporal logics

Religious temporalities coexisted with "standard" Gregorian temporalities in Canadian calendars as they did in Trinidad, and shaped the "day," "month," and "year." Paper calendars came pre-printed, and digital calendars pre-programmed, with national, provincial, cultural, and religious holidays "through a Gregorian medium" (Birth, 2013) with a Christian inflection: Christmas Day and Good Friday are statutory holidays across the country.

\section{Insert Figure 3 about here}

Figure 3. First Seder

Figure 3 comes from the large-format calendar a participant kept on the kitchen counter. This participant explained that her family had formerly used a Jewish calendar

A Jewish calendar runs from, a year is from Rosh Hashanah, so it would start in September. [...] We always had it 'cause it was more accurate than a regular calendar about Jewish holidays. 'Cause it'll say Rosh Hashanah is here, but actually it starts the night before, right? And the Jewish calendar would actually indicate that better than any regular calendar would.

She had replaced the Jewish calendar for two reasons. First, it included days with contextual meanings that were not significant to her and took up the space she needed for her own documentation.

It was from some charity group and it obviously did some fundraising by allowing people to mark their mother's birthday and father's birthday, and stuff in there, so the spaces were really small on the calendar.

Second, the Jewish calendrical logic was not helpful when calculating longer time periods in relation to the Gregorian calendar: "It always irritates me having this Jewish calendar that the months don't really add up with your regular Roman calendar, or whatever you call it." She had therefore replaced it with "a standard, commercial calendar with, a lot of white space on it" to afford her own documentation. 
Although the new calendar was good enough for secular life, it did not provide the helpful information about the calculation of Jewish holidays that the old calendar had. The "regular" calendar treats Passover as though it begins at midnight, not at sunset. The participant had to document this herself, writing "first seder" on the first day of Passover, which according to this calendar is the evening of the day before Passover begins.

For this participant, articulation work included amending the "standard, regular" calendar with the correct timing of the beginning of Jewish holidays. However, that work began at the beginning of each year with the selection of an appropriate calendar. Jewish temporality at the day level became one of the affordances, along with sufficient space for writing, she sought in a new calendar. However, since Gregorian/commercial time dominated in her everyday life, she did not want a calendar organized by Jewish calendrical logics at the month or year scale.

Religious and secular temporalities played out differently for a Christian clergy person, who used a paper planner provided by the church.

Insert Figure 4 about here.

\section{Figure 4: Celebrating St Andrew's Day}

This planner was organized by the Gregorian rather than the Christian liturgical year; it began on January 1st rather than the first day of Advent. It was organized weekly beginning with Sunday, and included the liturgical seasons and festivals as annotations within the Gregorian logic. At the "week" level we saw conflicts between sacred and secular temporalities.

Sunday was a work day for the clergy person, so her "weekend" included Monday, a work day in the standard work week. Her planner came pre-printed with saints' days, and St Andrew's Day is recorded as being November 30. However, since that day fell on a Friday that year, the participant had to write the feast day in on the Sunday following, though some congregations might attend a St Andrew's Day service on a Friday. Even within the context of a planner created to facilitate clergy work, the weekly schedule of Sunday worship conflicted with annual schedule of saints' days and the secular Monday-to-Saturday week.

Months and years: astronomical versus commercial, embodied, and other temporalities

"Monthly" bills arrived with variable billing dates, and documenting these helped participants stay on track with their payments. The month of 28 to 31 calendar days did not correspond to the embodied month of menstrual cycles for many participants. Their articulation work involved recording their menstrual periods against the backdrop of the Gregorian calendar month, as illustrated in Figure 1. Some used apps, which predicted the length of the cycle based on past durations. We saw one app that proclaimed a cycle of 32 days. In this case, the cognitive artifact did little to help the participant whose last four physical "months" ranged from 20 to 50 days in duration.

At the timescale of the year, Figures 1-4 give evidence of Gregorian and Jewish temporalities, as well as biographical (Figure 1 includes birthdays). Participants documented anniversaries of other kinds, sometimes including how many years since someone was born, was married, or had died. Three participants kept calendars with no year recorded, just the month and day, to document the annual 
cycle of anniversaries. Student calendars began in September, referencing the K-12 or postsecondary school year. The taxation year entrained recordkeeping to an April 30 submission date for most, though the income being taxed was that earned in the prior calendar year. Some self-employed participants paid some taxes in quarterly installments. Some participants documented the passage of the natural year and the seasons, annually recording the blooming of flowers or the first or last frost, which aligned roughly but never exactly with predictable calendar dates or the astronomical arrival of the seasons.

The first half of this section shows how participants used and customized cognitive artifacts to document the multiple temporalities and to reconcile multiple contextual meanings of time words relevant to their individual contexts. Attending to these practices brings visibility both to the complexity of everyday life and to the temporal flexibility and rigidity of cognitive artifacts. Breakdowns reveal the temporalities that underpinned the organization of the artifacts, including inconsistencies at different timescales. The second half builds on this base by focusing more holistically on the articulation work done by two participants, a musician who chose a pre-printed calendar to document times, and a small-scale farmer who created a customized system.

\section{Putting it all together: two case studies}

Both participants had a large number of contingencies and interdependencies to manage, and their articulation work included a number and range of temporalities. The musician juggled part-time contracts with ensembles in multiple cities within a $200 \mathrm{~km}$ radius of home, took one-off gigs, and taught students, both privately and with an established music school. His work was therefore entrained with orchestra schedules and the activities of families whose children sought to schedule music lessons. The farmer grew vegetables, which she sold in the autumn, providing weekly "market baskets" for prepaid subscribers and selling directly to walk-up customers. Her work was entrained both to the growing season, for which she documented vegetable seed selection, planting, tending, and harvesting, and to the autumn market.

They each used a primary cognitive artifact or suite of artifacts to document their work demands in tabular format, and each talked about and allowed us to photograph these. Their artifacts differed in medium and type (the musician used a single paper planner and the farmer used a spreadsheet with a suite of worksheets) but each operated on a year's timescale, though when that year started and ended varied. The musician included non-work items, such as car oil changes, in his planner; the farmer used a completely different agenda to document non-work events like dental appointments. Finally, the primary focus of their temporal documentation work differed. Although the musician had projects such as readying a piece for performance, his articulation work with his calendar focused on juggling events and appointments with individuals and organizations and their varying temporalities. Although the farmer had appointments like the weekly farm market, the main focus of her spreadsheets was managing the project of the farm season.

The next two subsections provide details on broader contexts and the documentation practices of the two cases.

"It's all subject to change." An off-the-shelf approach

The musician juggled a complex set of interdependent work roles with different temporalities. These included playing for several orchestras in multiple cities, most of which required a commute, taking gigs as they came up, teaching for music schools, and teaching private lessons. He observed, "I'd be working 
full-time [laughs]. But it can't always be done;" there were too many contingencies and overlaps. "I don't really have a full contract with any place" and it was rare to be asked to substitute for another performer who was ill: "It's hard to balance everything out."

The different roles exhibited seasonal patterns, and performing and teaching were entrained to different drivers over the course of the year. The performance year included the orchestra season, which started "the end of September/October," along with summer festivals. Most students were children who took lessons between September and June, "that ten-month academic year block," although some adult students preferred to learn over the summer because "they have more down time." We interviewed the musician at the end of August, which was a "really slow" period. Summer festivals had ended, and calls were just starting to come in for lessons: "Usually student lessons they book in September, October. By the time October hits, that's when everyone that wanted the lessons at least, signed up." So although this was a busy period of planning and preparation, not a lot of money was coming in. "Most of my profit was just gone to my general bills and then expenses."

In addition to accommodating these annual cycles, the musician had to arrange student lessons to accommodate any performance opportunities that might come up during the week:

The last couple years I stopped booking many students on Thursday night, Friday night, Saturday night, because usually, that's kind of the bulk of the performance time. So I try to squeeze most of them in like earlier in the week. A few years ago I would just put them like any spare time...But then the calls from the orchestras did come in, and then all of Thursday night and Saturday night has to be moved. But now I know usually my early Saturday mornings are fine, early Sunday mornings are fine. And then Mondays, Tuesdays, Wednesdays I probably won't get called for anything.

At the same time, he also had to entrain music lessons with his students' other weekly extracurricular activities, and with their parents' lives, both of which were more intense during the school year.

I guess in the summer the students are more accommodating because they don't have any other commitments. It doesn't always work like this during the academic year. Because often a lot of the kids you know, on Wednesday it will be hockey, Thursday basketball or whatever. And if you don't show up on that one Saturday morning, then the lesson's gone. Some people get upset and in the past I have had people stop, or try to find other teachers because they don't want any rescheduling. Like, that was set. Or some parents want the weekend off. So it's Friday night, they're not doing anything until Monday. And you're like, 'you know, cut me some slack guys! [laughs] I'll come to your house even!' So it depends on how flexible the people are, what time of the year it is.

The musician's articulation work therefore had somewhat contradictory goals: ensuring he was available to take longer-term orchestra contracts, which were predictable, often better-paying, and might lead to other performance opportunities, and at the same time fitting in enough student lessons to earn enough money to pay the bills. His employment was constrained not only by the annual educational and orchestra cycles, but also by weekly patterns of performances and student and family activities. He described how he began to document his commitments at the beginning of the academic and performance year.

The different orchestras I play with, some of them will give me a schedule ahead of time. So I'll 
print out several schedules and I'll try to cross-reference them as I'm getting bookings for other orchestras. Sometimes I'll get a call a week before with a group, then I might have to cancel, switch something around. But usually if I have something ahead of time, that's the foundation. I'll start with the groups that give me a steady contract. Then I teach for one small private studio. So again, they book the students and you're booked for like a year. So I know that every Saturday morning little Timmy's gonna come for his lesson. And usually they'll block a few students at a time. So I often I'll just pencil it into my schedule on a week-by-week basis.

The musician's primary tool documenting time was a portable paper planner that covered year from January to December and displayed a week per two-page spread. "Even though my schedule runs in the academic year, just for taxes I have to have [the calendar year]."

\section{Insert Figure 5 about here.}

Figure 5. The musician's calendar

He had recently bought this calendar in advance of the September start to the season. "It was actually hard for me to find. Everything [available now] is the academic year. [...] This is the best one I could get for the most reasonable price at this time of year." He liked several elements of the layout: "a little bit more space [than his previous year's planner], and I've got the whole week ahead of time. I can't deal with the books that have one page per day. You need to see a few days ahead. Often orchestra blocks will be the three days in a row. So you kind of have to see stuff spaced out. If I need to leave the city l'Il need to see when it's happening."

However, the planner was entrained to commercial time. It operated on the logic of a "work day," prioritizing the period between 7am and $6 \mathrm{pm}$. The period after 6 was compressed into very little space and given a different colour. Much of the musician's work took place in the evening, "after hours." The calendar also assumed a Monday to Friday "week," assigning full columns to those days but relegating Saturdays and Sundays each to half of the final column. The musician's calendar was largely unpopulated between Monday and Friday, but Sundays had a lot of appointments "crushed up."

One downside was they only go from 7am to $6 \mathrm{pm}$. Cause you'll have rehearsals sometimes that run until like $10 \mathrm{pm}$. So you'll see here I still have other little chunks. $8 \mathrm{pm}$ I had a lesson but the calendar ends at 6 . I've got the [City 8 Orchestra], this kid cancelled so I wrote 'no lesson Charlie,' I had a coaching at night....again 7 to 9, chamber rehearsal. A lesson with a student at 8:30, because the adult students are, that time's fine. And yeah, your Sunday's crushed up [in the planner], but I still have to go until 5 .

Because performance work was unpredictable, juggling lessons and "squeezing in a student" was a large component of his articulation work:

For example, I know that next week I've got three students coming. And then just as stuff comes I'Il pencil it in around it. So if I have to reschedule because I have a performance conflict, that's when it can be a little bit complicated...because you have one hour or half hour slots. And you can't all of a sudden move everyone like, 'Oh, could, all the Monday students go to Tuesday?' And that's when the one kid will agree to Tuesday, someone's gonna agree to Wednesday, someone will try to double up the following week by showing earlier... And then that's when the arrows start happening and it gets a little bit complicated. Here it looks like I had to cancel something so I just crossed that out. I had another orchestra that I just had to cancel [City 4 
Opera] here. It was just too spaced out and two other orchestras needed me at the same time. So I kind of prioritized.

The musician's reference to "pencilling something in" was not a metaphor, but a literal strategy for documenting the commitments he expected to be contingent, like student lessons, in a way that afforded revision.

That's why I use pencil; just in case I need to erase it and let's say someone else calls me, or then I can just maybe do a few makeup lessons with students that I missed...like a couple weeks earlier. So that lets me at least manage it a little bit better.

Where erasing and rewriting was impossible, he crossed items out and used arrows to indicate moved commitments. When we asked if his system had ever failed him, he responded "Yeah. I mean a couple times I might have accidentally moved two students at the same time, because the arrow went to the wrong spot."

The musician's articulation work was shaped by the temporal contingencies of his work, but also by the affordances of his paper calendar, including its dominant commercial temporality. Although the tool was not optimized to meet his temporal documentation needs, he used flexible techniques (writing in pencil, crossing out, using arrows to indicate rescheduling) to make it work for him, even though it was not foolproof.

\section{"You kind of have to work backwards." A do-it-yourself approach}

The farmer told us that her season began in the winter: "If you do your seed order in January or February you're usually guaranteed the varieties that you want and the quantities that you want." Seeding began in March or April, but was contingent on the weather: "It depends where you are and depends what the Spring is like, I guess. Could be April, could be May." The busy season began in May and June:

Once it's May you're generally past the risk of frost date. So a lot of things go into the garden and your soil temperatures are warm enough that we'd start growing, so weeding becomes a task. You're planting, you're weeding, you're picking, you're sowing. July can be busy, it's fairly steady through the summer. It really depends on the weather how crazy the fieldwork schedule is. And then the fall for me is very busy. September, October, and into November is usually pretty crazy. September is busy 'cause I've started selling, there's some big harvest tasks and there's still often weeding and planting. So that's for me that transition month. October the planting is done, there might still be weeding and then marketing starts taking time. [...] But the field season is pretty much done unless you have a greenhouse by the end of November, early December. But even that depends a lot on the weather.

Although she started her gardening year by planning her seed orders, she explained that she began with the end in mind, focusing on how much income she needed to earn and what she would like to include in each week's market baskets.

You kind of have to work backwards, money and shares I want to end up with to make it viable. So to raise that much money, how many shares? Say I decided I wanted to try to give beets three times. If I can grow a nice size beet I want to give people five beets in each box. So then 
you just have the math. So how many total beets do we need for the whole season? Then I have a safety margin that differs depending on the crop.

As a result, her articulation work was characteristic of project management (Larson and Gray, 2014), but each step was fraught with uncertainty that required flexibility and accommodation:

You could have problems at the seed stage, the seedling stage, maybe you luck out after you've transplanted something, maybe you have a hail storm. You have a beautiful planting of greens, a big hailstorm shreds it.

Although there were fixed times when things needed to be done during the growing season, her work was entrained more to the weather than to the calendar date. As a result, she planned by week and built in a great deal of day-to-day flexibility, at least until the beginning of market season entrained her work to weekly Saturday delivery dates:

Farming isn't always easy and the income is not always high, but what I have is a lot of time [laughs] in my schedule, in my life and how I do things. So if I feel like going to the farm late one morning because I don't have seedlings to water and staying and doing laundry and cooking something for the week, I don't have to regiment my time between personal life and business life. [...] It's a lot more regimented for me in the fall 'cause harvest days have to be harvest day. Although there's some flexibility in that. Often I can pick things a half day sooner or a half day later depending on what the weather is going to look like. But by [laughs] 5:30 on Saturday morning the car's gotta be full. At some appropriate point before that it's gotta be picked and washed and bagged and binned. And then ready to go.

The farmer's articulation work began with her crop planning Excel spreadsheet, which contained multiple datasheets. The Crop Planning sheet highlighted her income targets for market vegetables, local farmgate sales, and late summer harvest baskets. It specified the number and range of vegetable types she wanted to provide in order to make her income targets. This spreadsheet referenced market time implicitly, with the "boxes" the customers received standing in for weeks. This datasheet was organized alphabetically by vegetable and documented the number of weekly market boxes that would include each vegetable, and the quantity of each vegetable per box.

She used the crop planning datasheet as the basis for creating the other datasheets in the Excel document. First was her seed order. After considering the number and timing of vegetables she wanted to deliver, she ordered seeds, selecting what varieties met her needs for taste, appearance, growing method, time to maturity, amount and type of field space required, and, from her own experience, ease or finickiness to grow.

\section{Insert Figure 6 about here}

Figure 6. The farmer's planting dates spreadsheet

Once she had confirmed the specific varieties she was going to plant, she was able to create her planting schedule, which took temporal information both from the crop planning data sheet and from the calendar of her market weeks.

My planting schedule I make up ahead of time. All the vegetables and the varieties. Then I have 
to figure out, what is my best date that I think I need to plant things on. So what gets added here from my seed order is the days to maturity, and then the planting method. I figure out whether I'm going to direct seed something or transplant it. And then again it's kind of working backwards a little bit. When do I want this to be ready? How many days to maturity? In my past experience, does that actually hold true? I just have this calendar in front of me where I've noted my [autumn market] pick-up dates. For this round of pick-ups I want this planting to be ready. So you just kind of work backwards. And then you're doing quantities too for things that you're transplanting. [...] So what you work backwards from is the days to maturity from transplant, so that's the day it needs to go in the field to be ready for when I want it. So when do I need to seed it for the seedlings to be big enough.

She then transformed this by-plant-variety datasheet into monthly custom calendars, which she created herself from a bare $7 \times 4$ table template, entering the name of the months, the dates, and adding an image of a vegetable relevant to the month in question. She printed these calendars as single pages and took them into the field with her. Although she had a paper planner for the non-farming parts of her life, she preferred to create her own tool rather than use a "pre-fab planner" that allocated time to appointment slots or days rather than the weeks that were the pacer for her farming activities:

A lot of them are geared toward business people, they have the appointment times. I've never found that useful. It's more a day thing. Or a week thing, 'cause really what I often think of is weeks for the farm.

She also preferred the paper calendar over the calendaring and note-taking functions on her mobile phone because she could set the current month's page into a clear plastic sleeve to protect it from the inevitable dirt and water it would encounter in use.

The things that get written down on this [calendar sheet] ahead of time are my little categories, like, seed, direct seed, and transplant. So I just go through the spreadsheet and I would do it month by month. Okay, for April what is everything that needs seeding, transplanting, or direct seeding in the garden? And that gets written down. So then the week before or certainly in the week of I'm looking ahead at what are the critical planting tasks? 'Cause if I can keep on that schedule it's better [laughs]. There's certain things that are flexible. If you miss a week weeding it's not good because the weeding's going to take you longer but you don't necessarily lose something. If you don't plant something on time [laughs] you get into trouble.

\section{Insert Figure 7 about here}

\section{Figure 7. Farmer's monthly field calendar}

During the growing season, then, the farmer's articulation work was shaped by several temporalities: the projected fall market basket "weeks" by which she set her goals and timeline, the local growing season, climate, and weather; the time-to-maturity and planting (direct seed or transplant) and cultivation needs of each vegetable type and each variety. On her wall was a photocopied month page from a biodynamic calendar (e.g., Wildfeuer, 2021) that identified cycles of auspicious days for activities related to leafy, fruiting, flower, and root crops ("It's basically cosmic forces on plants"). She had decided to try this method, both to see whether it made a difference to the quality of her harvest and to add some shape to her field weeks, since it gave her a predetermined four-day repeating cycle of plant types to focus on. She handwrote these days on her monthly paper field calendar. 
Once market season began, she tracked her subscribers' contact information, orders, pick-ups, and payments. From her customer spreadsheet, she printed paper sheets and put them into a binder, which accompanied her to the market each week. She also tracked payments from subscribers and walk-up customers in a bank deposit spreadsheet to make sure she was able to reconcile her accounts. As a small business operator like the musician, her financial documentation was entrained to the calendar year. She paid her Harmonized Sales Tax (HST) quarterly and had created a tax spreadsheet that she used to record her business expenses using taxation categories. Using a spreadsheet for this task let her copy and paste the relevant information into her online tax form each quarter.

For farm taxes I do my HST quarterly. So everything gets organized by the tax categories of expenses for the farm. I probably sit down once or twice a month and go through. [laughs] So when I do my HST returns I can just cut and paste. Everything just comes out for the quarter by date. And then goes here and then I can submit it electronically now. Which is nice.

The farmer's articulation work was shaped equally by calculable project-based quantities and timelines leading up to market sales in the autumn, and by the need to be respond flexibly to the unpredictable conditions of farming. These contingencies led her to create her own tools that responded to her needs, both in terms of the temporalities and categories included, and in terms of the physical format.

\section{Discussion and Conclusion}

Savolainen (2006, p.123) argues that the temporality of information practices "becomes a more interesting subject of research when temporal factors are reviewed in relation to other contextual factors." This article has presented both the "hows" and the "whats" of the articulation work involved in documenting time within and across the domains of everyday life. It has contributed to conversations within $\mathrm{HCl}$ and $\mathrm{CSCW}$ that demonstrate the situated, material, and contextually relevant ways that participants use cognitive artifacts (Hutchins 1999) like planners, calendars, schedules, and spreadsheets to document time. It has contributed to scholarship within documentation studies and other disciplines that considers how individuals' documentary practices draw from, participate in, and contribute to the maintenance of broader communities, institutions, infrastructure, and discourses. It demonstrates that, although the work of keeping track is uniquely enacted by each individual with respect to their own context, it is also embedded within and organized by larger socio-cultural systems.

If we are to respond to Savolainen's (2006) call to consider temporal factors in relation to other contextual factors, we must also acknowledge that "temporal factors" are not unitary, but multiple. The articulation work required to keep track in everyday life is also embedded in and contributes to temporal systems and infrastructures, and this finding contributes to scholarship on both the "how" and the "what."

Adam $(1990,1995)$ observed that individuals and organizations are skilled at conflating multiple temporalities and operating as though they were coherent, and the same could be said for documenting them. Overall, participants skilfully navigated the pre-printed or pre-programmed temporal logics of their calendars and planners. In active use, they layered on multiple and contingent temporalities work shifts, school deadlines, romantic dates, twice-yearly dentist appointments, illnesses, family events, holidays, vacations, in many cases experiencing no incongruities between the temporal logics built into the tools and their purposes for using them. 
The conflicts, breakdowns, and incongruities that they did experience served to reveal the temporal infrastructures on which their cognitive artifacts are built (Star 1999). Conflicts between different contextual meanings of time words revealed assumptions built into the design of cognitive artifacts and indicated both the limits and the possibilities of off-the-shelf tools. In some cases, participants took the opportunity to modify or reverse-engineer; for example, by using a term like "lunch" flexibly so that it related to multiple and contingent periods of clock time, to writing "in the margins" when their gig work day did not align with the Monday-Friday 9-6 full-time commercial work expectations built into a planner, to creating a class of contingent (pencilled-in) calendar entries that they could modify, shorten, or move as conditions changed.

Cognitive artifacts that worked at one level of specificity did not always work at all levels, and participants built these features into their articulation work, from the initial steps of choosing or creating one or more cognitive artifacts that would meet their needs, to selecting the level(s) of granularity at which to document in order to ensure flexibility at the week level or the ability to view and therefore plan around commitments several days ahead, to creating a system of customized spreadsheets in order to document planting, germination, growing, and harvest times of different vegetables.

Cognitive artifacts are structured in relation to dominant cycles and may hide (or reveal) other temporalities. Either way, a blank calendar is not empty, and users work within and around the constraints even though the tools themselves may render that work invisible. Temporal logics therefore shaped, but did not fully determine, both the cognitive artifacts participants used to do their articulation work and the work itself. Empirically, this article has also shown that the entries in planners, calendars, and schedules can offer a window into everyday life as multifaceted (Ocepek 2018) and polychronic.

Individual practices shaped and were shaped by the material and the temporal affordances of the cognitive artifacts they created and used: the portability of a planner, the erasability of pencil marks on paper, and the customizability of do-it-yourself tools and the ability of a lightweight paper calendar in a plastic sleeve to withstand the physical conditions of the farm field. From a design perspective, our participants showed that time has many shapes, very few of which are built into the cognitive artifacts they used. The farmer's choice of tabular formats for tools she designed herself illustrates the dominance of this form, but the resurgence in popularity of customizable paper notebooks for planning demonstrates a recognition that tabular forms will not work for all. Even within a tabular form, designers could build in room for maneuvering, such as allowing users to determine durations, beginning and end dates and times of built-in cycles such as days and weeks, and adding the ability for a calendar entry to transcend its square, comic-book style, to emphasize that it holds significance beyond its clock-time duration. 


\section{References}

ADAM, B. 1990. Time and social theory, Cambridge, Polity Press.

ADAM, B. 1995. Timewatch: the Social Analysis of Time, Cambridge, Polity Press.

BEECH, S., GEELHOED, E., MURPHY, R., PARKER, J., SELLEN, A. \& SHAW, K. 2004. The Lifestyles of Working Parents: Implications and Opportunities for New Technologies. Bristol: HP Laboratories.

BIRTH, K. 2013. Calendars: Representational homogeneity and heterogeneous time. Time \& Society, 22, 216-236.

BOWKER, G. C. \& STAR, S. L. 1999. Sorting things out: classification and its consequences, Cambridge, MA, MIT Press.

BRAUN, V. \& CLARKE, V. 2006. Using thematic analysis in psychology. Qualitative Research in Psychology, 3, 77-101.

BRUSH, A. J. B. \& TURNER, T. C. 2005. A survey of personal and household scheduling. ACM International Conference on Supporting Group Work - GROUP. ACM.

CANADIAN INSTITUTES OF HEALTH RESEARCH; NATURAL SCIENCES AND ENGINEERING RESEARCH COUNCIL OF CANADA; SOCIAL SCIENCES AND HUMANITIES RESEARCH COUNCIL OF CANADA. 2018. Tri-council Policy Statement: Ethical Conduct for Research Involving Humans - TCPS2. Ottawa, Ontario: Public Works and Government Services Canada.

CORBIN, J. M. \& STRAUSS, A. 2007. Basics of Qualitative Research: Techniques and Procedures for Developing Grounded Theory., Thousand Oaks, CA, Sage.

COURTRIGHT, C. 2007. Context in information science research. In: CRONIN, B. (ed.) Annual Review of Information Science and Technology. Medford, NJ: Information Today.

CRABTREE, A., HEMMINGS, T., RODDEN, T. \& MARIANI, J. 2003. Informing the development of calendar systems for domestic use. European Conference on Computer Supported Cooperative Work ECSCW. Kluwer Academic Publishers, 119-138.

DAVIES, E. 2007. Epistemic practices of theatre production professionals: an activity theory approach. The University of Western Ontario.

DITTMAR, A. \& DARDAR, L. 2014. Studying ecologies of calendar artifacts. ACM International Conference Proceeding Series.

ELIOT, K., NEUSTAEDTER, C. \& GREENBERG, S. 2007. StickySpots: using location to embed technology in the social practices of the home. International Conference on Tangible, Embedded and Embodied Interaction - TEI. ACM.

FLAHERTY, M. G. 2003. Time work: Customizing temporal experience. Social psychology quarterly, 66, 17-33.

GRIMES, A. \& BRUSH, A. J. 2008. Life scheduling to support multiple social roles. ACM Conference on Human Factors in Computing Systems - CHI. Florence, Italy: ACM.

HANCOCK, P. \& REHN, A. 2011. Organizing Christmas. Organization, 18, 737-745.

HJØRLAND, B. SCERRI, E. \& DUPRE, J. 2011. Forum: the philosophy of classification. Knowledge Organization, 38, 9-24.

HOLSTEIN, J. A. \& GUBRIUM, J. F. 2011. The constructionist analysis of interpretive practice. In: DENZIN, N. K. \& LINCOLN, Y. S. (eds.) The SAGE Handbook of Qualitative Research. Thousand Oaks, CA: Sage.

HOCHSCHILD, A. R. 1997. The time bind: when work becomes home and home becomes work. New York, Metropolitan Books.

HUTCHINS, E. 1999. Cognitive artifacts. The MIT Encyclopedia of the cognitive science. Cambridge, MA: MIT Press.

JOHANSSON, V. 2012. A time and place for everything? Social Visualisation Tools and Critical Literacies, Valfrid. 
LARSON, E. W. \& GRAY, C. F. 2014. Project management: the managerial process, New York, McGraw-Hill Education.

LESHED, G. 2012. Slowing down with personal productivity tools. Interactions, 19, 58-63.

LESHED, G., HAKANSSON, M. \& KAYE, J. J. 2014. Our life is the farm and farming is our life': Home-work coordination in organic farm families. ACM Conference on Computer Supported Collaborative Work- CSCW.

LESHED, G. \& SENGERS, P. 2011. I lie to myself that I have freedom in my own schedule': Productivity tools and experiences of busyness. ACM Conference on Human Factors in Computing Systems CHI.

MCCOY, L. 2009. Time, self and the medication day: A closer look at the everyday work of 'adherence'. Sociology of Health and IIIness, 31, 128-146.

MCKENZIE, P. J. 2020. Informational boundary work in everyday life. In: SUNDQVIST, A., BERGET, G., NOLIN, J. \& SKJERDINGSTAD, K. I., eds. Sustainable Digital Communities: 15th International Conference, iConference 2020, Borås, Sweden, March 23-26, 2020. 96-103. https://doi.org/10.1007/978-3-030-43687-2 8

MCKENZIE, P. J. \& DAVIES, E. 2021. Documentary tasks in the context of everyday life. Library Trends 69, 492-519.

NEUSTAEDTER, C., BRUSH, A. J. B. \& GREENBERG, S. 2009. The calendar is crucial: Coordination and awareness through the family calendar. ACM Transactions on Computer-Human Interaction, 16, Article 6.

OCEPEK, M. G. 2018. Bringing out the everyday in everyday information behavior. Journal of Documentation, 74, 398-411.

PALEN, L. 1999. Social, individual and technological issues for groupware calendar systems. ACM Conference on Human Factors in Computing Systems - CHI. ACM.

PAYNE, S. J. 1993. Understanding calendar use. Human-Computer Interaction, 8, 83-100.

PEACOCKE, T. W. 2017 (Director). The throuple.Toronto: Canadian Broadcasting Corporation.

PLAISANT, C., CLAMAGE, A., HUTCHINSON, H. B., BEDERSON, B. B. \& DRUIN, A. 2006. Shared family calendars: Promoting symmetry and accessibility. ACM Transactions on Computer-Human Interaction, 13, 313-346.

POLLAK, A. 2017. Visual research in LIS: Complementary and alternative methods. Journal of the American Society for Information Science and Technology, 39, 97-108.

SABELIS, I. 2001. Time management: Paradoxes and patterns. Time \& society, 10, 387-400.

SAVOLAINEN, R. 2006. Time as a context of information seeking. Library \& Information Science Research, 28, 110-127.

SCULLIN, M. K., MULLET, H. G., EINSTEIN, G. O. \& MCDANIEL, M. A. 2015. Prospective memory. In: SMELSER, N. J. \& BALTES, P. B. (eds.) International Encyclopedia of the Social \& Behavioral Sciences. 2nd ed.: Pergamon.

SHANKAR, K. 2007. Order from chaos: the poetics and pragmatics of scientific recordkeeping. Journal of the American Society for Information Science and Technology, 58, 1457-1466.

SHANKAR, K. 2009. Ambiguity and legitimate peripheral participation in the creation of scientific documents. Journal of Documentation, 65, 151-65.

SOUTHERTON, D. 2006. Analysing the temporal organisation of daily life: social constraints, practices and their allocation. Sociology, 40, 435-454.

STAR, S. L. 1999. The ethnography of infrastructure. American Behavioral Scientist, 43, 377-391.

SWAN, L. \& TAYLOR, A. S. 2004. An ethnography of lists in mothers' work. ACM Conference on Human Factors in Computing Systems - CHI.

SYMES, C. 2011. Time and motion: Chronometry and the railway timetables of New South Wales, 
1855-1906. KronoScope, 11, 145-165.

THAYER, A., BIETZ, M. J., DERTHICK, K. \& LEE, C. P. 2012. I love you, let's share calendars: calendar sharing as relationship work. ACM Conference on Computer Supported Collaborative Work CSCW. Seattle, Washington, USA: ACM.

TOMITSCH, M., GRECHENIG, T. \& WASCHER, P. 2006. Personal and private calendar interfaces support private patterns: diaries, relations, emotional expressions. Nordic Conference on Human-Computer Interaction - NordiCHI. ACM.

TRACE, C. B. 2002. What is recorded is never simply "what happened": record keeping in modern organizational culture. Archival science, 2, 137-159.

TRACE, C. B. 2007. Information creation and the notion of membership. Journal of documentation, 63, 142-163.TUNGARE, M., PÉREZ-QUIÑONES, M., SAMS, A. 2008. An exploratory study of personal calendar use. arXiv:0809.3447v1 [cs.HC] 19 Sep 2008 https://arxiv.org/pdf/0809.3447

WHITTAKER, S. 2011. Personal information management: From information consumption to curation. In: CRONIN, B. (ed.) Annual Review of Information Science and Technology. Medford, NJ: Information Today.

WILDFEUER, S., ED. 2021. Stella Natura 2021 Biodynamic Planting Calendar: Planting Charts and Thought-Provoking Essays, Kimberton, PA, Stella Natura. 
Figures:

Figure 1: Documenting multiple temporalities

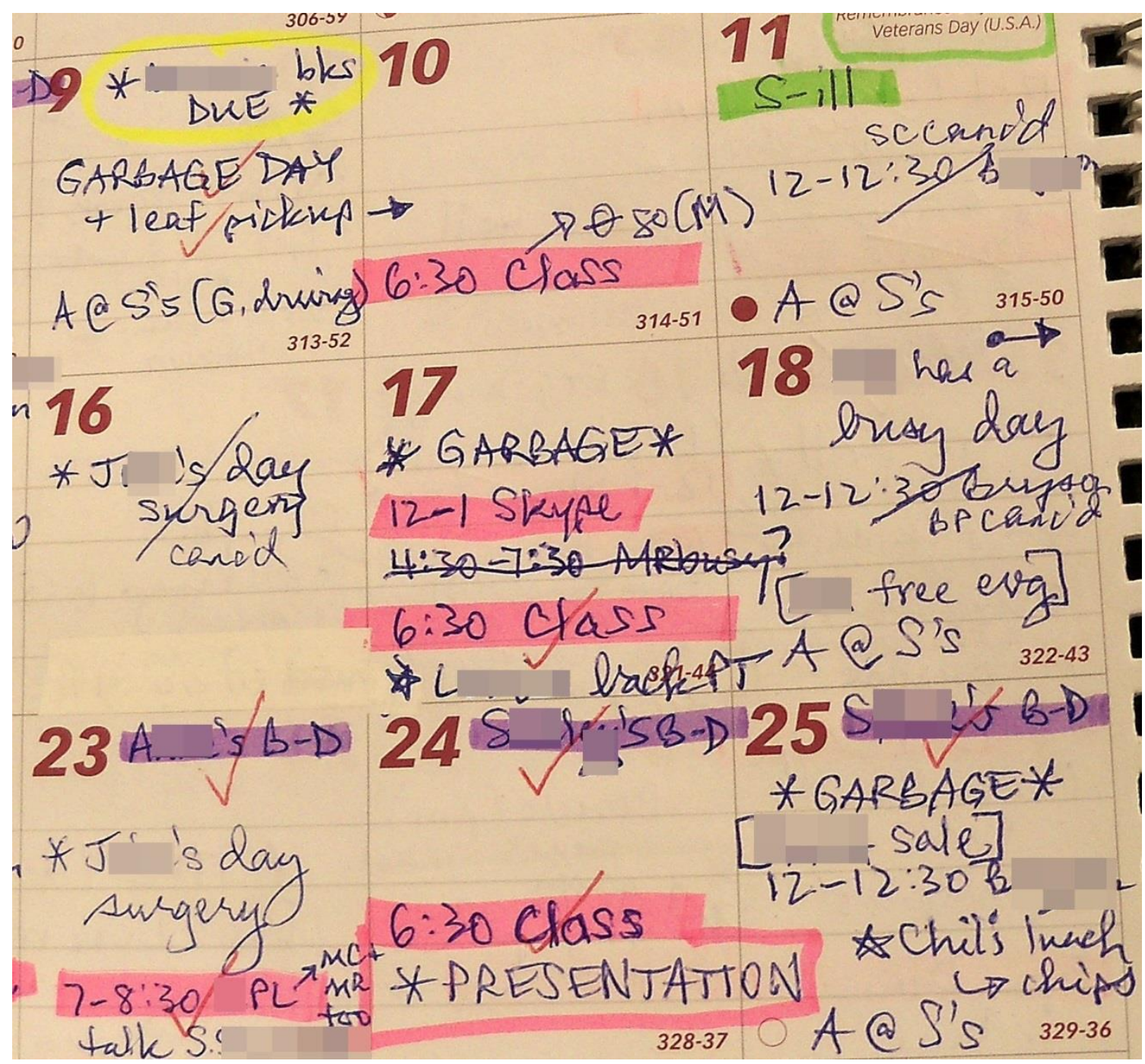


22

Figure 2: Lunch in the restaurant

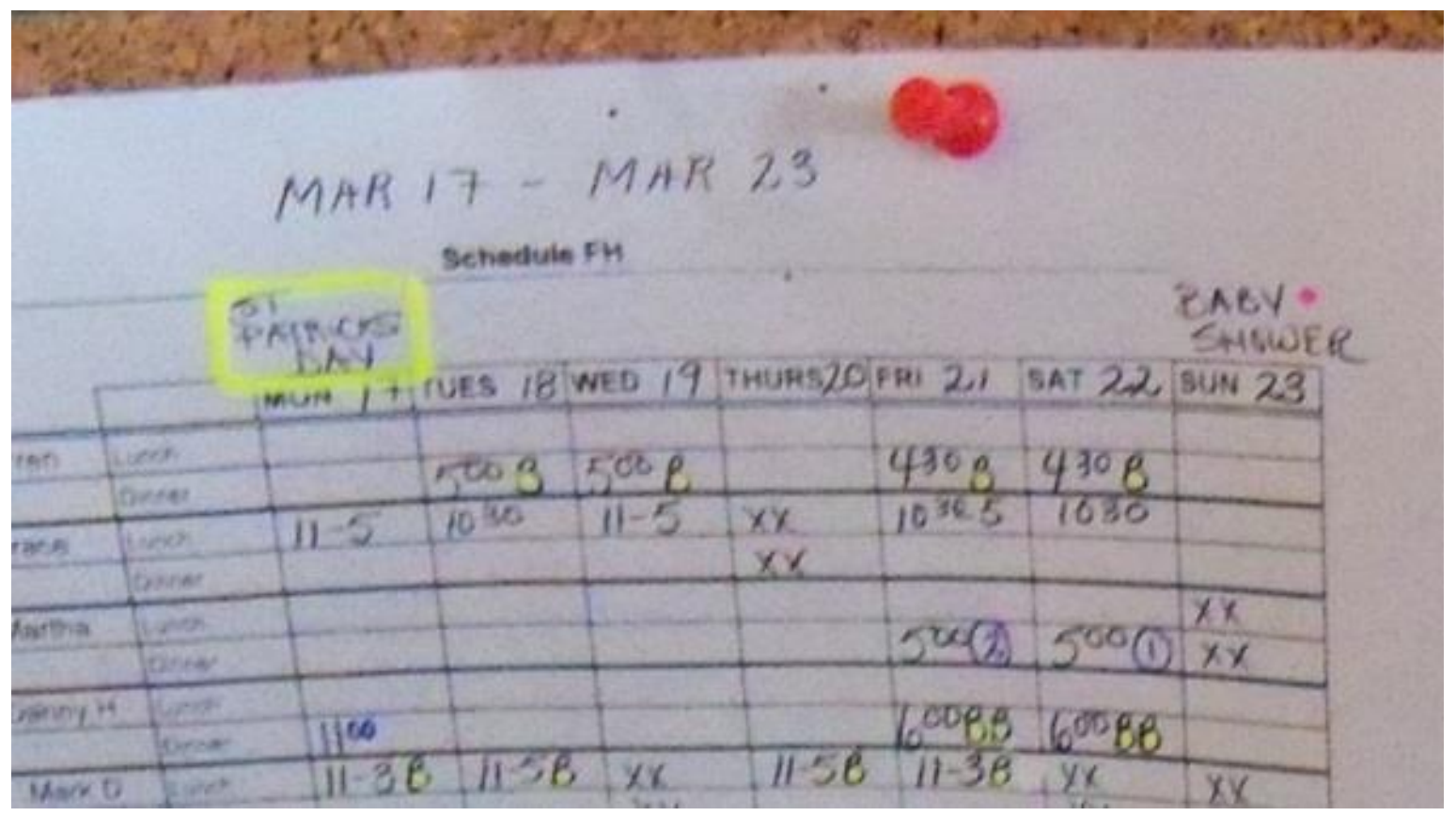

Figure 3: First Seder

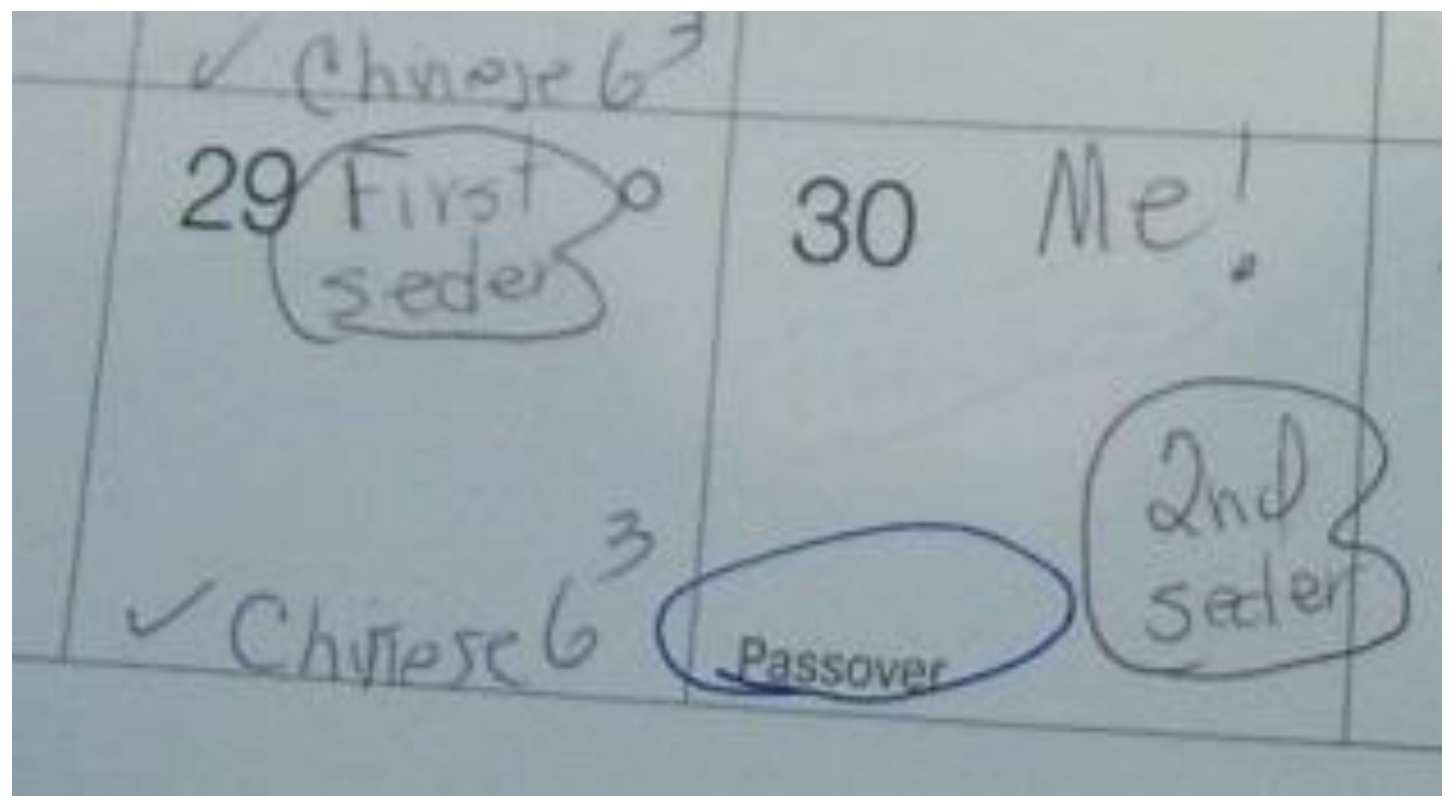


Figure 4: Celebrating St Andrew's Day

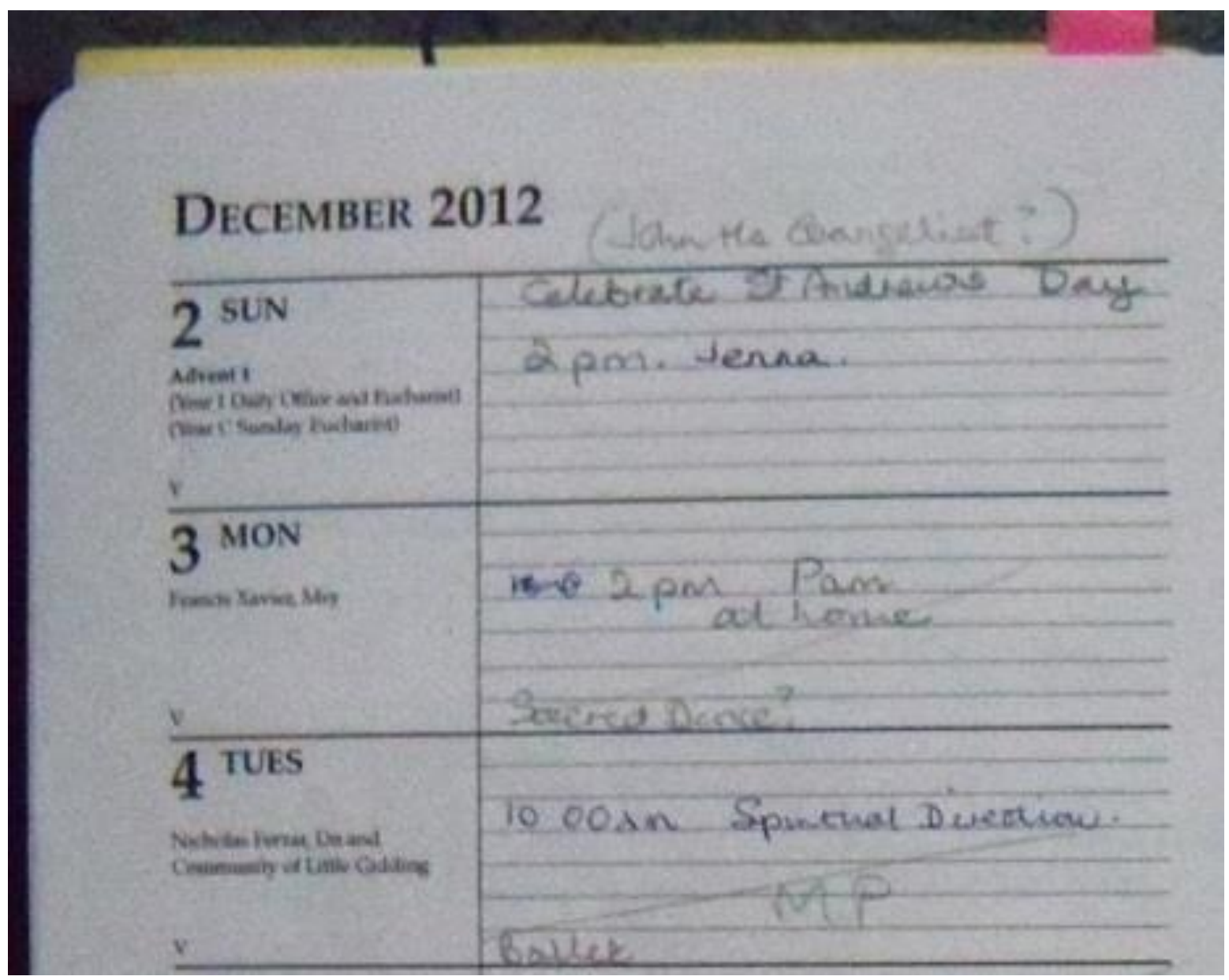


Figure 5: The musician's agenda

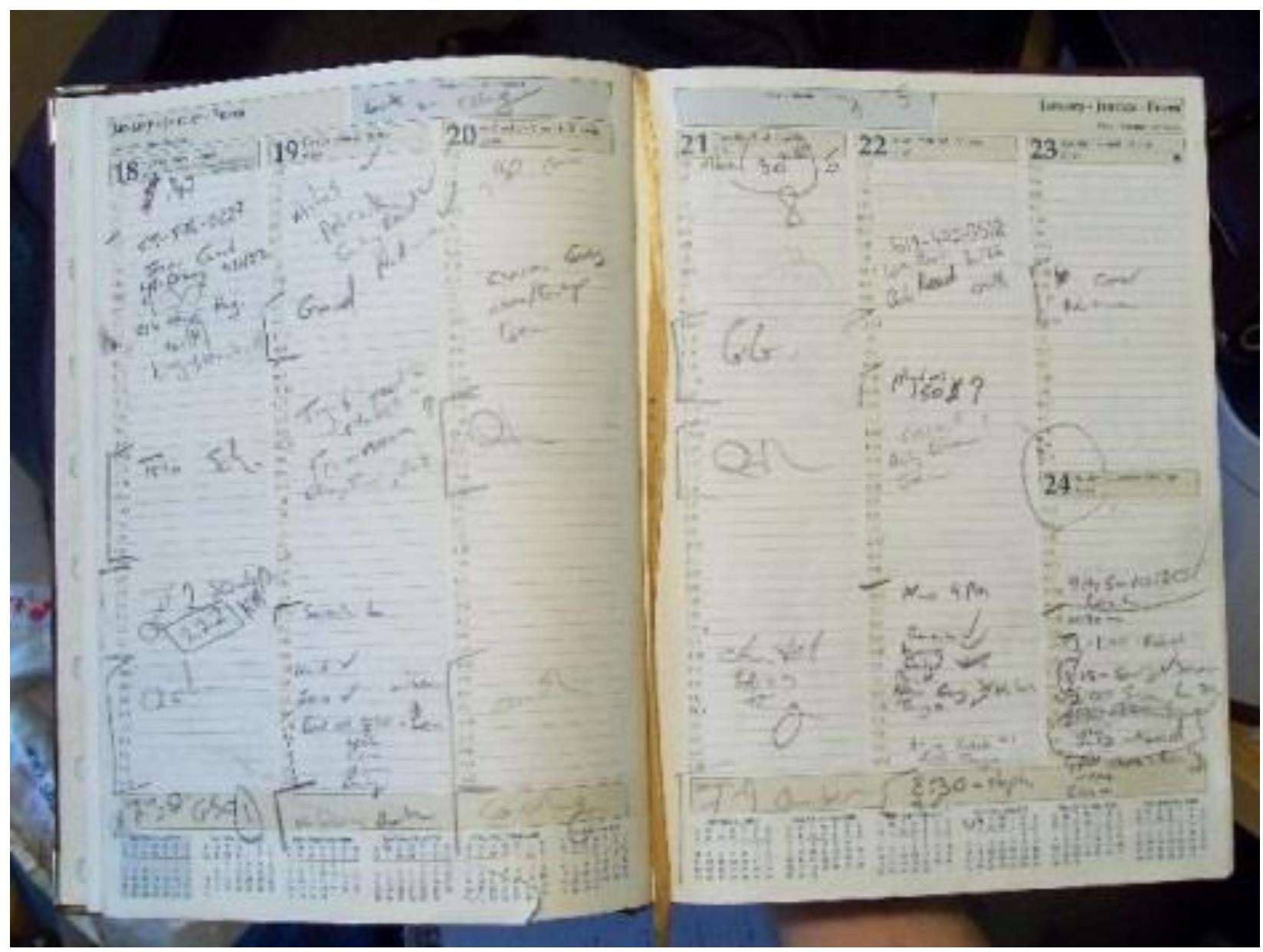


Figure 6. The farmer's planting schedule

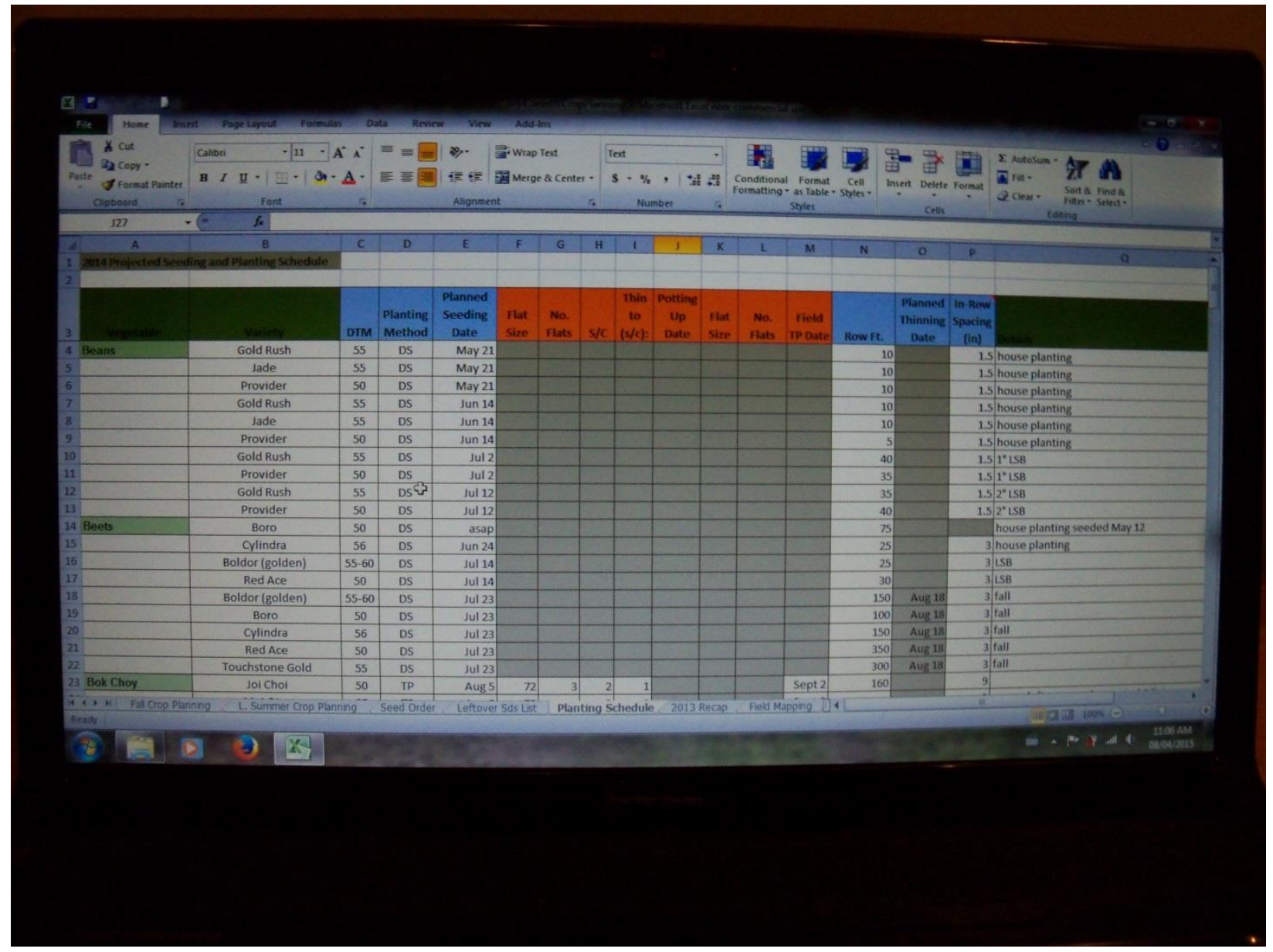


Figure 7: The farmer's monthly field calendar

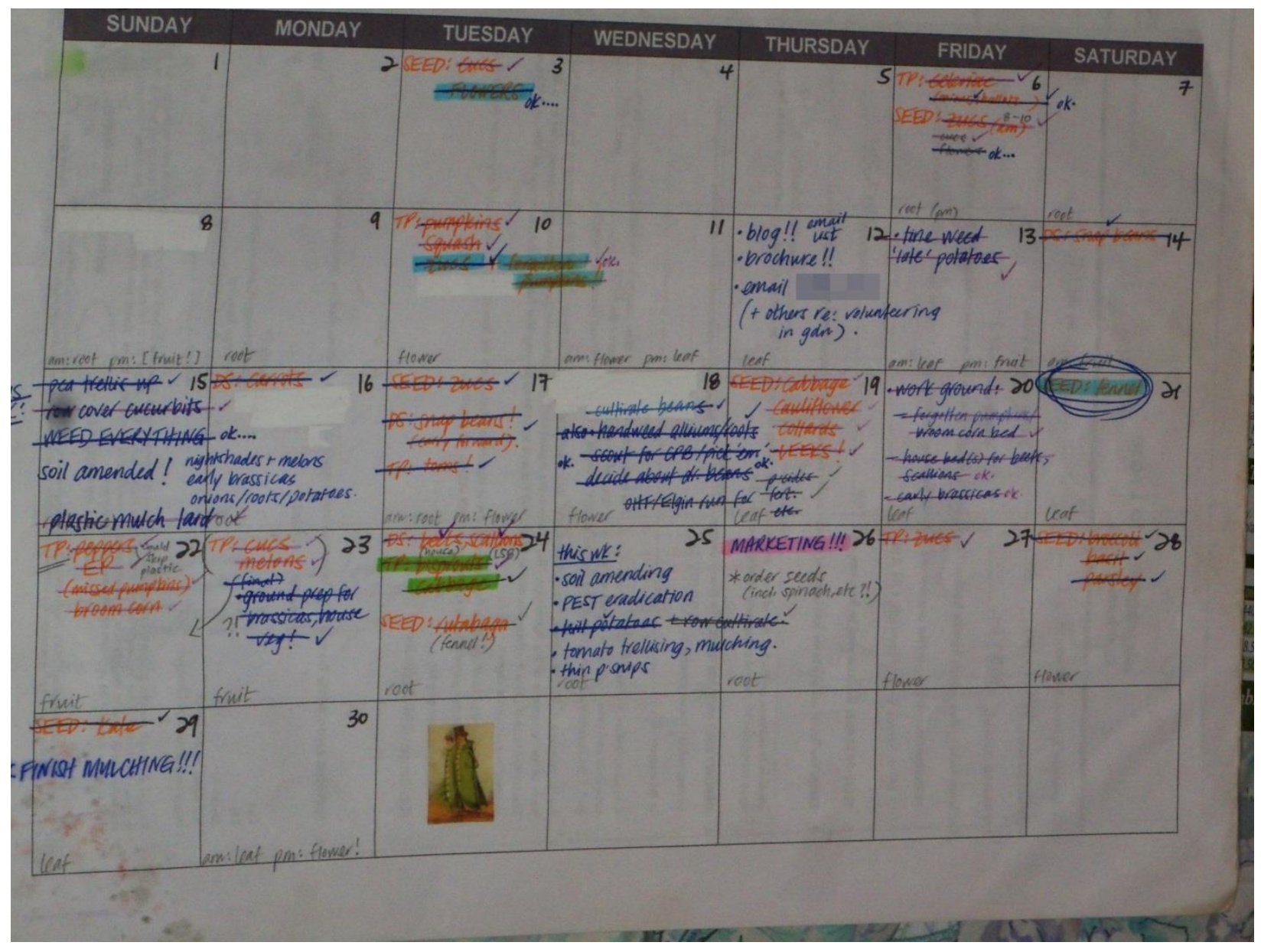

